\title{
Synthesis of Fluorinated Amphiphilic Block Copolymers Based on PEGMA, HEMA, and MMA via ATRP and CuAAC Click Chemistry
}

\author{
Fatime Eren Erol, ${ }^{1}$ Deniz Sinirlioglu, ${ }^{2}$ Sedat Cosgun, ${ }^{3}$ and Ali Ekrem Muftuoglu ${ }^{4}$ \\ ${ }^{1}$ Department of Chemistry, Faculty of Arts and Science, Yildiz Technical University, Davutpasa Campus, \\ Esenler, 34220 Istanbul, Turkey \\ ${ }^{2}$ Department of Chemistry, Faculty of Arts and Science, Fatih University, Buyukcekmece, 34500 Istanbul, Turkey \\ ${ }^{3}$ Department of Chemistry, Medical Laboratory Techniques, Vocational School of Medical Sciences, Fatih University, \\ Maltepe, 34840 Istanbul, Turkey \\ ${ }^{4}$ Department of Chemical Engineering, Faculty of Chemical and Metallurgical Engineering, Yildiz Technical University, \\ Davutpasa Campus, Esenler, 34220 Istanbul, Turkey
}

Correspondence should be addressed to Ali Ekrem Muftuoglu; ekremm@yildiz.edu.tr

Received 6 May 2014; Accepted 27 July 2014; Published 19 August 2014

Academic Editor: Ali Akbar Entezami

Copyright (C) 2014 Fatime Eren Erol et al. This is an open access article distributed under the Creative Commons Attribution License, which permits unrestricted use, distribution, and reproduction in any medium, provided the original work is properly cited.

Synthesis of fluorinated amphiphilic block copolymers via atom transfer radical polymerization (ATRP) and Cu(I) catalyzed Huisgen 1,3-dipolar cycloaddition (CuAAC) was demonstrated. First, a PEGMA and MMA based block copolymer carrying multiple side-chain acetylene moieties on the hydrophobic segment for postfunctionalization was carried out. This involves the synthesis of a series of $\mathrm{P}$ (HEMA-co-MMA) random copolymers to be employed as macroinitiators in the controlled synthesis of P(HEMA-co-MMA)-block-PPEGMA block copolymers by using ATRP, followed by a modification step on the hydroxyl side groups of HEMA via Steglich esterification to afford propargyl side-functional polymer, alkyne-P(HEMA-co-MMA)-block-PPEGMA. Finally, click coupling between side-chain acetylene functionalities and 2,3,4,5,6-pentafluorobenzyl azide yielded fluorinated amphiphilic block copolymers. The obtained polymers were structurally characterized by ${ }^{1} \mathrm{H}-\mathrm{NMR},{ }^{19} \mathrm{~F}-\mathrm{NMR}$, FT-IR, and GPC. Their thermal characterizations were performed using DSC and TGA.

\section{Introduction}

The perfluoroalkyl moieties in amphiphilic molecules provide distinct properties, such as hydrophobicity and lipophobicity, high thermal and chemical stability, excellent mechanical properties at extreme temperatures, low refractive index, and a strong tendency to self-assemble [1-6]. A great deal of attention has been paid to the incorporation of fluorinated groups into synthetic materials, which combine the advantages of both fluorinated groups and other polymers [710]. Controlled radical polymerization (CRP) can serve as a powerful synthetic tool in the production of well-defined fluorinated polymers with various architectures having predetermined chain lengths and low polydispersities. Fluorinated block copolymers have been synthesized previously via CRPs, involving nitroxide mediated radical polymerization (NMP) $[11,12]$, reversible addition fragmentation chain transfer polymerization (RAFT) $[13,14]$, and atom transfer radical polymerization (ATRP) [15-19].

Amphiphilic block copolymers consisting of hydrophobic fluorinated blocks and hydrophilic poly[poly(ethylene glycol)methyl ether methacrylate] (P(PEGMA)) have been synthesized [20-23]. P(PEGMA) block, prepared by CRPs, is a versatile polymer in fine-tuning hydrophobic/hydrophilic balance of the amphiphile since lengths of both P(PEGMA) and PEG side-chains can be altered. Besides, P(PEGMA) segments may introduce favorable characteristics to the copolymers including water solubility, low toxicity, and high 
biocompatibility [24-26]. 2,3,4,5,6-Pentafluorobenzyl containing segments have been employed as the hydrophobic part in several studies and have accounted for the abovementioned properties stemming from perfluoroalkyl moieties [27-29]. The overall macromolecules have potential in applications involving nonlinear optics, rheology modifiers, and antifouling coatings.

Quite recently, click reactions have attracted considerable attention in synthetic polymer chemistry owing to their high specificity, high tolerance of functional groups, and quantitative reaction yields. $\mathrm{Cu}(\mathrm{I})$ catalyzed Huisgen 1,3dipolar cycloaddition (CuAAC), which occurs between an azide and an alkyne to give 1,2,3-triazole ring [30, 31], has emerged as a powerful tool in the preparation of versatile macromolecular structures when used in conjunction with controlled/living radical polymerization techniques $[9,32]$.

Herein, we report the synthesis of a fluorinated amphiphilic block copolymer on the basis of combined ATRP and $\mathrm{Cu}(\mathrm{I})$ catalyzed Huisgen 1,3-dipolar cycloaddition (CuAAC) methods. To the best of our knowledge, this is the first study to report the preparation of perfluoroalkylated amphiphilic block copolymer brushes by this approach. Furthermore, the method allows for facile adaptation of a variety of other click moieties and fine-tunes their concentration without altering the size of hydrophobic segment.

\section{Experimental}

2.1. Materials. Methyl methacrylate (MMA, 99\%, Aldrich) and 2-hydroxyethyl methacrylate (HEMA, 99\%, Aldrich) were distilled before use. Poly(ethylene glycol) methyl ether acrylate (PEGMA, $M_{n}=480 \mathrm{~g} / \mathrm{mol}$, Aldrich) was passed through basic alumina column to remove the inhibitor Ethyl $\alpha$-bromoisobutyrate (EBIB, 98\%, Aldrich), 2,3,4,5,6-pentafluorobenzyl chloride (Aldrich 99\%), $\mathrm{CuCl}(\geq 99.99 \%$, Aldrich), $\mathrm{CuBr}$ (98\%, Aldrich), sodium azide $\left(\mathrm{NaN}_{3}\right.$, SigmaAldrich), 2,2-bipyridine (bpy, 99\%, Fluka), $N, N, N^{\prime}, N^{\prime \prime}, N^{\prime \prime}$ -pentamethyldiethylenetriamine (PMDETA, 99\%, Aldrich), methanol ( $\geq 99.9$, Aldrich), $N, N^{\prime}$-dicyclohexylcarbodiimide (DCC, 99\%, Aldrich), 4-(dimethylamino) pyridine (DMAP, $\geq 99.99 \%$, Aldrich), propiolic acid (99\%, Aldrich), and N,Ndimethylformamide (DMF, 99\%, Aldrich) were used as received.

2.2. Typical Procedure for the Random Copolymerization of HEMA with MMA via ATRP $(\mathbf{l a}-\boldsymbol{d})$. Molar ratio of MMA and HEMA was varied to get random copolymers with different HEMA contents. For instance, to obtain $\mathrm{P}(\operatorname{HEMA}(20)-c o-M M A(80))$, in which the numbers in parenthesis refer to $\mathrm{v} / \mathrm{v}$ percentages, reagents at the molar ratio of $[\mathrm{HEMA}] /[\mathrm{MMA}] /[\mathrm{EBIB}] /[\mathrm{CuCl}] /[\mathrm{bpy}]: 18 / 82 / 1 / 1 / 2.5$ were added. HEMA (1.72 g, $1.60 \mathrm{~mL}, 13 \mathrm{mmol})$, MMA (6.01 g, $6.40 \mathrm{~mL}, 60 \mathrm{mmol}), \mathrm{CuCl}(0.072 \mathrm{~g}, 0.72 \mathrm{mmol})$, ethyl $\alpha$ bromoisobutyrate (EBIB, $0.142 \mathrm{~g}, 0.72 \mathrm{mmol}$ ), and bipyridine (bpy, $0.145 \mathrm{~g}, 0.093 \mathrm{mmol}$ ) were mixed in a Schlenk tube equipped with a magnetic stirring bar, to which $5.3 \mathrm{~mL}$ of methanol ([monomer] $/$ solvent $=1.5: 1 \mathrm{v} / \mathrm{v})$ was added. The tube was degassed by three freeze-pump-thaw cycles.
The polymerization flask was placed on a magnetic stirrer and kept there for a given period at room temperature, after which the reaction was terminated by dipping the tube into liquid nitrogen. The mixture was diluted with THF and passed through a silica gel column to remove the complex salts. The solution was then concentrated and precipitated into 10fold excess hexane. The precipitate was collected by filtration and dried in a vacuum oven at $30^{\circ} \mathrm{C}$ overnight. (68\% conv., ${ }^{1} \mathrm{H}-\mathrm{NMR}\left(\mathrm{CDCl}_{3}, \mathrm{ppm}\right): \delta=0.88-1.36$ (s, $\alpha-\mathrm{CH}_{3}, \mathrm{MMA}$ and HEMA), 1.5-2.1 (s, - $\mathrm{CH}_{2}$, MMA and HEMA), 3.55 (s, - $\left.\mathrm{OCH}_{3}, \mathrm{MMA}\right), 3.78$ ( $\left.\mathrm{t},-\mathrm{CH}_{2} \mathrm{OH}, \mathrm{HEMA}\right), 4.05$ ( $\mathrm{t},-\mathrm{OCH}_{2}$, HEMA). FT-IR $\left(\mathrm{cm}^{-1}\right): 3540$ (-OH stretching), 2957 (-CH aliphatic stretching), 1726 ( $-\mathrm{C}=\mathrm{O}$ stretching), and 1151 (-C$\mathrm{O}-\mathrm{C}-$ stretching).

2.3. Block Copolymerization of PEGMA Using Poly(HEMAco-MMA) Macroinitiator via $\operatorname{ATRP}(\mathbf{2 b}, \mathbf{2 d})$. In a typical procedure, $\mathrm{P}(\mathrm{HEMA}(20)$-co-MMA(80)) (1b) macroinitiator (0.41 g, $0.045 \mathrm{mmol})$, PEGMA ( $8.72 \mathrm{~g}, 18 \mathrm{mmol})$ monomer, $\mathrm{CuBr}(0.007 \mathrm{~g}, \quad 0.045 \mathrm{mmol})$, and PMDETA (0.016 g, $0.09 \mathrm{mmol}$ ) were dissolved in methanol/water mixture $(\mathrm{MeOH} /$ water $=2: 1 \mathrm{v} / \mathrm{v})$ in a Schlenk tube equipped with a magnetic stirring bar. The reaction mixture was degassed by three freeze-pump-thaw cycles, backfilled with nitrogen, and kept in a magnetic stirrer at room temperature. After the given period, the Schlenk tube was immersed into liquid nitrogen to terminate the reaction. Upon reaching room temperature, the mixture was diluted with THF and passed through a silica gel column to remove the copper salt. The solution was completely dried in a rotary evaporator and then subjected to dialysis against regularly replaced distilled water to remove PEGMA monomer (spectra/Por membranes, cutoff $1,000 \mathrm{Da}$ ). The solution was again evaporated to dryness in a rotary evaporator. The residue was dissolved in THF and precipitated into 10 -fold excess hexane. The precipitate was collected by filtration and dried in vacuo overnight. Yield: 75\%. ${ }^{1} \mathrm{H}-\mathrm{NMR}\left(\mathrm{CDCl}_{3}, \mathrm{ppm}\right): \delta=0.84-1.4$ (s, $\alpha-\mathrm{CH}_{3}$, MMA and HEMA), 1.8-2.1 ( $\mathrm{s},-\mathrm{CH}_{2}, \mathrm{MMA}$ and HEMA), 2.3-2.5 (d, - $\mathrm{CH}_{2}$, PEGMA), 3.38 (s, $\mathrm{CH}_{3} \mathrm{O}-$, PEGMA), 3.55 (s, $\mathrm{CH}_{3} \mathrm{O}-$, MMA), 3.65 ( $\mathrm{t},-\mathrm{CH}_{2} \mathrm{O}-$, , PEGMA), $3.84(\mathrm{t}$, $-\mathrm{OCH}_{2}-$, HEMA), 4.1-4.2 ( $\mathrm{t},-\mathrm{CH}_{2} \mathrm{OH}$ and $-\mathrm{CH}_{2} \mathrm{CH}_{2} \mathrm{O}$, HEMA and PEGMA). FT-IR $\left(\mathrm{cm}^{-1}\right): 3550$ (-OH stretching), 2870 ( $-\mathrm{CH}$ aliphatic stretching), 1733 ( $-\mathrm{C}=\mathrm{O}$ stretching), and 1095 (-C-O-C- stretching).

2.4. Synthesis of Alkyne-P(HEMA-co-MMA)-block-PPEGMA $(3 \boldsymbol{b}, \mathbf{3} \boldsymbol{d})$. The reagents were used according to the following molar ratios: [side-chain $\mathrm{OH}] /[\mathrm{DCC}] /[\mathrm{DMAP}] /[$ propiolic acid]: 1/1.6/0.16/1.5. To obtain alkyne-P(HEMA-co-MMA)block-PPEGMA (3b, 3d), P(HEMA-co-MMA)-blockPPEGMA (2b, 2d) (0.5 g, $0.008 \mathrm{mmol})$, DCC $(0.053 \mathrm{~g}$, $0.256 \mathrm{mmol})$, DMAP $(0.003 \mathrm{~g}, 0.0256 \mathrm{mmol})$, and propiolic acid $(0.017 \mathrm{~g}, 0.24 \mathrm{mmol})$ were added in a round-bottom flask and dissolved in $50 \mathrm{~mL} \mathrm{CH}_{2} \mathrm{Cl}_{2}$ under stirring at room temperature. Then, the mixture was concentrated in the rotary evaporator and precipitated in 10-fold excess hexane. Yield: $87 \% .{ }^{1} \mathrm{H}-\mathrm{NMR}\left(\mathrm{CDCl}_{3}, \mathrm{ppm}\right): \delta=0.84-1.4\left(\mathrm{~s}, \alpha-\mathrm{CH}_{3}\right.$, MMA and HEMA), 1.8-2.1 ( $\mathrm{s},-\mathrm{CH}_{2}, \mathrm{MMA}$ and HEMA), 


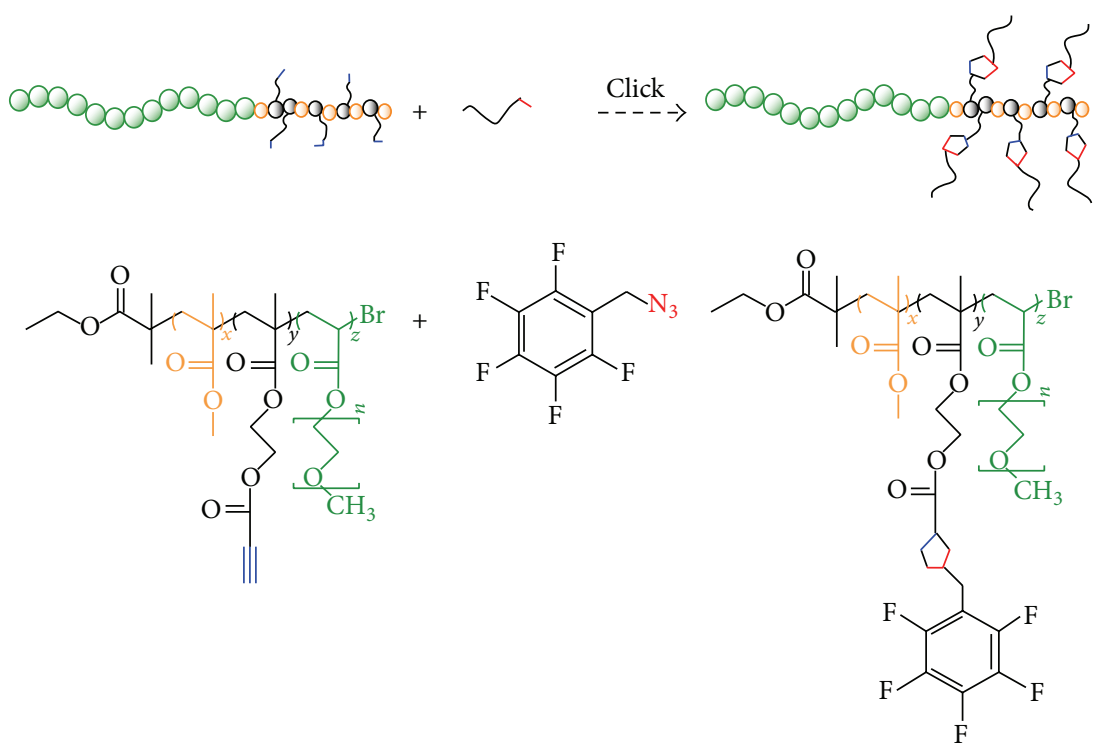

FIGURE 1: Schematic illustration of click coupling between PEGMA based amphiphilic block copolymers bearing pendant clickable sites and azide-functional group.

2.3-2.4 (d, - $\mathrm{CH}_{2}$, PEGMA), $2.57(\mathrm{~s},-\mathrm{OC} \equiv \mathrm{CH}) 3.38(\mathrm{~s}$, $\left.\mathrm{CH}_{3} \mathrm{O}-, \mathrm{PEGMA}\right), 3.55$ ( $\left.\mathrm{s}, \mathrm{CH}_{3} \mathrm{O}-, \mathrm{MMA}\right), 3.63$ ( $\mathrm{t},-\mathrm{CH}_{2} \mathrm{O}$, PEGMA), 3.82 ( $\left.\mathrm{t},-\mathrm{OCH}_{2}, \mathrm{HEMA}\right), 4.1-4.2\left(\mathrm{t},-\mathrm{CH}_{2} \mathrm{OH}\right.$ and $-\mathrm{CH}_{2} \mathrm{CH}_{2} \mathrm{O}$, HEMA and PEGMA). FT-IR $\left(\mathrm{cm}^{-1}\right): 3320$ ( $-\mathrm{C} \equiv \mathrm{CH}$ stretching), 2875 ( $\mathrm{CH}$ aliphatic stretching), 2350 ( $-\mathrm{C} \equiv \mathrm{CH}$ stretching), 1735 ( $-\mathrm{C}=\mathrm{O}$ stretching), and 1099 (-C-O-C- eter stretching).

2.5. Synthesis of 2,3,4,5,6-Pentafluorobenzyl Azide. $\mathrm{NaN}_{3}$ $(0.65 \mathrm{~g}, 0.01 \mathrm{~mol})$ and 2,3,4,5,6-pentafluorobenzyl chloride $(2 \mathrm{~g}, 0.008 \mathrm{~mol})$ were dissolved in $50 \mathrm{~mL} \mathrm{~N}, N$-dimethylformamide in a round-bottomed flask equipped with a magnetic stirrer. The reaction solution was stirred for $24 \mathrm{~h}$ at room temperature [33-36]. Then, DMF was removed under reduced pressure in a rotary evaporator and the remaining solid was dissolved in $\mathrm{CH}_{2} \mathrm{Cl}_{2}$. The mixture was washed thoroughly with water. The organic layer was removed and recovered solid was dried under vacuum at $25^{\circ} \mathrm{C}$. Yield: $80 \%$. ${ }^{1} \mathrm{H}-\mathrm{NMR}\left(\mathrm{CDCl}_{3}, \mathrm{ppm}\right): \delta=3.67\left(\mathrm{~s},-\mathrm{CH}_{2}\right)$. FT-IR $\left(\mathrm{cm}^{-1}\right)$ : 2110 ( $-\mathrm{N}_{3}$ stretching), 1650-1500 ( $-\mathrm{C}=\mathrm{C}-$ stretching), and 1235 (-CF stretching). ${ }^{19} \mathrm{~F}-\mathrm{NMR}\left(\mathrm{CDCl}_{3}, \mathrm{ppm}\right): \delta=o:-142$ (2F), $p:-151(1 \mathrm{~F}), m:-161(2 \mathrm{~F})$.

2.6. Click Coupling Reaction of Alkyne-P(HEMA-co-MMA)block-PPEGMA with 2,3,4,5,6-Pentafluorobenzyl Azide (4). The reagents were used according to the following molar ratios: [side-chain acetylene]/[- $\left.\mathrm{N}_{3}\right] /[\mathrm{CuBr}] /[\mathrm{PMDETA}]: 1 / 1 /$ 2.5/2.5. Alkyne-P(HEMA-co-MMA)-block-PPEGMA (0.3 g, $0.005 \mathrm{mmol}$ ) (3b) was dissolved together with 2,3,4,5,6pentafluorobenzyl azide $(0.016 \mathrm{~g}, 0.07 \mathrm{mmol})$ in degassed DMF under nitrogen. To the reaction mixture $\mathrm{CuBr}(0.025 \mathrm{~g}$, $0.176 \mathrm{mmol})$ and PMDETA $(0.031 \mathrm{~g}, 0.176 \mathrm{mmol})$ were added, while the solution was being purged with nitrogen. Then, it was stirred for $48 \mathrm{~h}$ at room temperature, after which, the mixture was diluted with THF and passed through a silica gel column to remove the copper salt [34-36]. Finally, excess solvent was removed in a rotary-evaporator and the resultant solution was poured into 10 -fold excess hexane for precipitation. The solid was collected by filtration and dried in vacuo overnight. (For 2,3,4,5,6-pentafluorobenzyl functional P(HEMA-co-MMA)-block-PPEGMA, yield: $83 \%,{ }^{1} \mathrm{H}-\mathrm{NMR}$ $\left(\mathrm{CDCl}_{3}, \mathrm{ppm}\right): \delta=0.84-1.58$ (s, $\alpha-\mathrm{CH}_{3}, \mathrm{MMA}$ and HEMA), 1.83 (s, $-\mathrm{CH}_{2}$, MMA and HEMA), 2.30 (d, $-\mathrm{CH}_{2}$, PEGMA), 3.38 (s, $\mathrm{CH}_{3} \mathrm{O}_{-}$, PEGMA), 3.56 (s, $\mathrm{CH}_{3} \mathrm{O}-, \mathrm{MMA}$ ), 3.65 (t, - $\mathrm{CH}_{2} \mathrm{O}$, PEGMA), 3.90 ( $\left.\mathrm{t},-\mathrm{OCH}_{2}, \mathrm{HEMA}\right), 4.0-4.17$ ( $\mathrm{t}$, $\mathrm{CH}_{2} \mathrm{CH}_{2}$ and $-\mathrm{CH}_{2} \mathrm{CH}_{2} \mathrm{O}$, HEMA and PEGMA), 4.47 (s, $\mathrm{CH}_{2}-\mathrm{N}_{3}$ ), 7.64 (s, $-\mathrm{CH}$, from triazole ring), FT-IR $\left(\mathrm{cm}^{-1}\right)$ : 2870 ( $-\mathrm{CH}$ aliphatic stretching), 1733 ( $-\mathrm{C}=\mathrm{O}$ stretching), and 1095 (-C-O-C- stretching)).

2.7. Characterizations. FT-IR spectra were recorded using a Bruker Alpha-P in ATR in the range of $4000-400 \mathrm{~cm}^{-1} .{ }^{1} \mathrm{H}-$ NMR spectra were recorded using a $400 \mathrm{MHz}$ Bruker Avance spectrometer in $\mathrm{CDCl}_{3}$. Chemical shifts are reported in ppm relative to TMS as internal standard.

Thermal stabilities of the membranes were analyzed by a PerkinElmer STA 6000 Thermal Analyzer. The samples $(\sim$ $10 \mathrm{mg}$ ) were heated between $30-750^{\circ} \mathrm{C}$ under $\mathrm{N}_{2}$ atmosphere at a scanning rate of $10^{\circ} \mathrm{C} / \mathrm{min}$. PerkinElmer JADE Differential Scanning Calorimetry (DSC) was used to investigate the thermal transitions of the samples. The samples $(\sim 10 \mathrm{mg})$ were put into aluminum pans and then heated to the desired temperature at a rate of $10^{\circ} \mathrm{C} / \mathrm{min}$ under nitrogen atmosphere.

Gel-permeation chromatography (GPC) measurements were performed on THF solutions of the polymers using an Agilent GPC 1100 instrument. The measurements were standardized against THF solutions of polystyrene standards. 


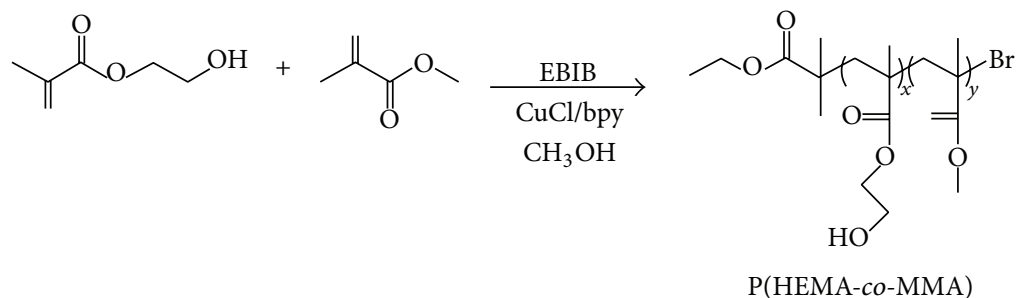

(1)

(1)

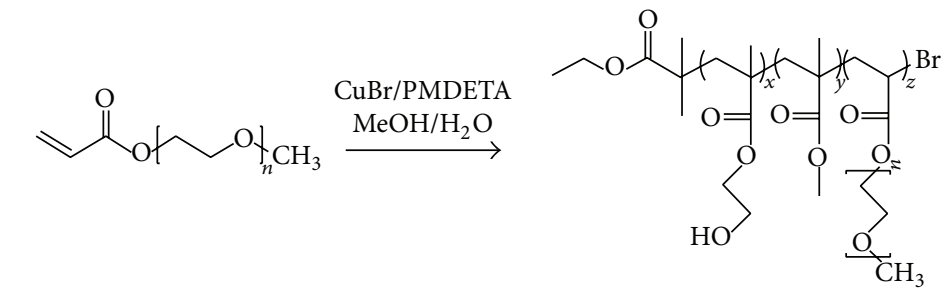

P(HEMA-co-MMA)-block-PPEGMA

(2)

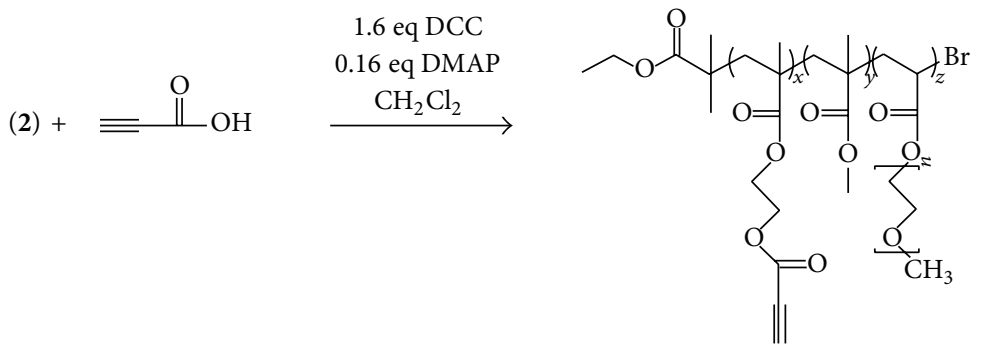

Alkyne-P(HEMA-co-MMA)-block-PPEGMA

(3)

(3) +

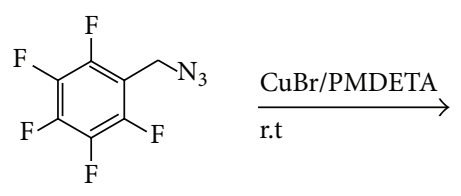<smiles>CCOC(=O)C(C)(C)CC(C)(CC(C)(CC(C)(C)C(=O)OCCOC)C(=O)OCCCOC(=O)c1cn(Cc2c(F)c(F)c(F)c(F)c2F)nn1)C(=O)OCCOC</smiles>

(4)

FIGURE 2: Synthesis of alkyne-P(HEMA-co-MMA)-block-PPEGMA (3) and its click coupling reaction (4).

\section{Results and Discussion}

A novel approach combining ATRP with $\mathrm{Cu}(\mathrm{I})$ catalyzed Huisgen 1,3-dipolar cycloaddition (CuAAC) in the preparation of a fluorinated amphiphilic block copolymer has been demonstrated (Figure 1). Synthesis of polymers based on MMA and PEGMA carrying clickable moieties for further functionalization was carried out in a three-step strategy, as depicted in Figure 2. First, a series of precursor random copolymers (1a-1d) P(HEMA-co-MMA) were prepared via ATRP of MMA and HEMA. In the second step, the obtained polymer was employed as a macroinitiator in ATRP of PEGMA to afford the block copolymer (2b, 2d), P(HEMAco-MMA)-block-PPEGMA. 
TABLE 1: Conditions ${ }^{\mathrm{a}}$ and results for the synthesis of P(HEMA-co-MMA).

\begin{tabular}{lccccccc}
\hline Entry & Comonomers in feed (\% volume) & Polymer & Time (h) & ${ }^{\mathrm{b}}$ Conv. (\%) & ${ }^{\mathrm{c}} M_{n, \mathrm{GPC}}$ & ${ }^{\mathrm{d}} M_{n, \text { theo }}$ & ${ }^{\mathrm{e}}$ PDI \\
\hline $\mathbf{1}$ & HEMA(5)-MMA(95) & $\mathbf{( 1 a )}$ & 17 & 91 & 9300 & 9420 \\
$\mathbf{2}$ & HEMA(20)-MMA(80) & $\mathbf{( 1 b )}$ & 12 & 68 & 5850 & 7360 \\
$\mathbf{3}$ & HEMA(30)-MMA(70) & $\mathbf{( 1 c )}$ & 10 & 60 & 5500 & 6690 \\
$\mathbf{4}$ & HEMA(50)-MMA(50) & $\mathbf{( 1 d )}$ & 7 & 43 & 4384 & 5100 \\
\hline
\end{tabular}

${ }^{\mathrm{a}}\left[\right.$ Monomer]/solvent $=1.5: 1 \mathrm{v} / \mathrm{v},[\mathrm{M}] /[\mathrm{I}] /[\mathrm{CuCl}] /[\mathrm{bpy}]: 100 / 1 / 1 / 2.5$, ethyl $\alpha$-bromoisobutyrate was used as an initiator, and temperature: r.t. ${ }^{\mathrm{b}}$ determined gravimetrically. ${ }^{\mathrm{c}}$ determined from GPC measurements. ${ }^{\mathrm{d}}$ calculated by using formula: $M_{n, \text { theo }}=M_{w \text {, monomer }} \times[$ Monomer $] /[$ Initiator $] \times$ Conv. + $M_{w \text {,initiator }}{ }^{\mathrm{e}}$ determined from GPC measurements.

Finally, propargyl moieties were introduced via the Steglich esterification between the hydroxyl side-functionalities of HEMA and propiolic acid. Alkyne-P(HEMA-coMMA)-block-PPEGMA (3b, 3d) was then click-coupled with model compound, namely, 2,3,4,5,6-pentafluorobenzyl azide to yield (4). Copolymerization of methyl methacrylate (MMA) and 2-hydroxyethyl methacrylate (HEMA) was carried out via ATRP using ethyl $\alpha$-bromoisobutyrate (EBIB), $\mathrm{CuCl}$, and bipyridine as initiator, catalyst, and ligand, respectively, at room temperature in methanol. Conditions and results are summarized in Table 1. Molar ratio of MMA and HEMA was varied to get random copolymers with different HEMA contents. For instance, to obtain $\mathrm{P}(\mathrm{HEMA}(20)-c o-\mathrm{MMA}(80))$, in which the numbers in parenthesis refer to $\mathrm{v} / \mathrm{v}$ percentages, reagents at the molar ratio of [HEMA]/[MMA]/[EBIB]/[CuCl]/[bpy]: 18/82/1/1/2.5 were added.

Chemical structures of the copolymers were identified using several techniques. The FT-IR spectra of four different compositions of copolymers $\mathrm{P}$ (HEMA-co-MMA) are given in Figure 3. The broad band at $3540 \mathrm{~cm}^{-1}$ due to the $-\mathrm{OH}$ stretching, increasing with the HEMA content in the copolymers, was an apparent characteristic peak of the series. The $\mathrm{CH}$ stretching appeared around $2957 \mathrm{~cm}^{-1}$. The characteristic $-\mathrm{C}=\mathrm{O}$ stretching band in both HEMA and MMA units in the copolymer occurred at $1726 \mathrm{~cm}^{-1}[37,38]$. The strong $-\mathrm{C}-\mathrm{O}-$ $\mathrm{C}-$ type ester stretching band appeared at $1151 \mathrm{~cm}^{-1}$ [38].

The ${ }^{1} \mathrm{H}$-NMR spectra of $\mathrm{P}$ (HEMA-co-MMA) copolymers are given in Figure 4. The signal for methyl protons of $-\mathrm{OCH}_{3}$ (a) in MMA units appeared at $3.55 \mathrm{ppm}[38,39]$. The signals of $\alpha-\mathrm{CH}_{3}$ protons were seen at $0.88-1.36 \mathrm{ppm}$ in both MMA and HEMA units, while for methylene protons they were in the range of $1.5-2.1 \mathrm{ppm}$. The signals at $3.78 \mathrm{ppm}(\mathrm{b})$ and $4.05 \mathrm{ppm}$ (c) correspond to $-\mathrm{CH}_{2} \mathrm{OH}$ and $-\mathrm{CH}_{2} \mathrm{O}$ protons, respectively [38].

Copolymer compositions from ${ }^{1} \mathrm{H}-\mathrm{NMR}$ were calculated by integral area of the $-\mathrm{OCH}_{3}$ and $-\mathrm{OCH}_{2}$ protons using the following [38]:

$$
\text { Molar percent of HEMA }=\frac{(1 b / 2)}{[(1 b / 2)+(1 a / 3)]} \times 100
$$

The copolymer compositions obtained from ${ }^{1} \mathrm{H}-\mathrm{NMR}$ agreed well with the charged monomer ratio in feed as shown in Table 2.

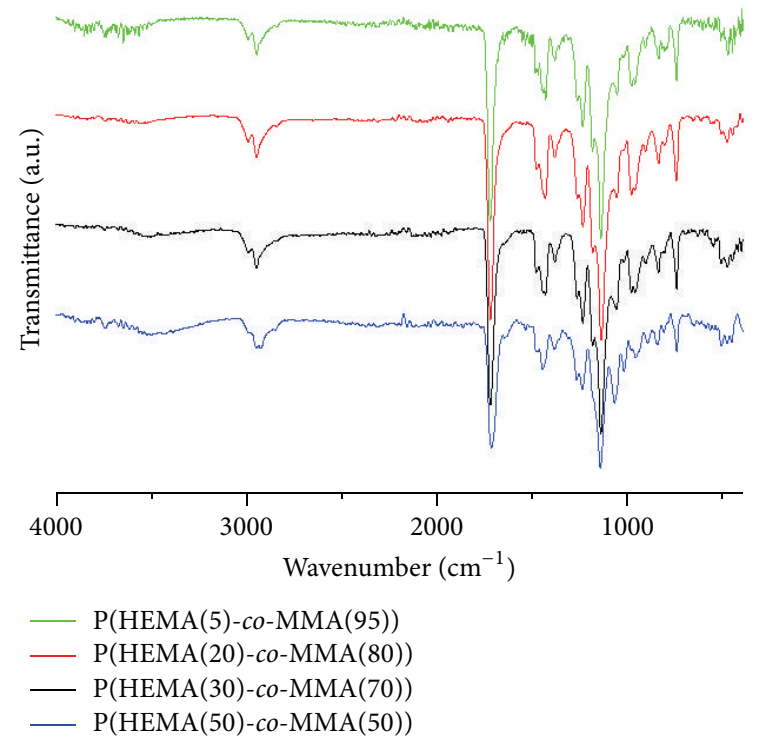

Figure 3: FT-IR spectra of P(HEMA-co-MMA) copolymers.

Polymerization of poly(ethylene glycol) methyl ether acrylate was carried out via ATRP using $\mathrm{P}(\operatorname{HEMA}(20)$-coMMA(80)) (1b) and P(HEMA(50)-co-MMA(50)) (1d) as macroinitiator and $\mathrm{CuBr} / \mathrm{PMDETA}$ as catalyst system at room temperature in methanol/water. Conditions and results are summarized in Table 3.

For both P(HEMA-co-MMA)-block-PPEGMA (2b, 2d) block copolymers, the ${ }^{1} \mathrm{H}$-NMR spectrum exhibited signals originating from $\alpha-\mathrm{CH}_{3}$ protons and $-\mathrm{CH}_{2}$ protons between 0.84-1.4 ppm and 1.8-2.1 ppm, respectively, in both MMA and HEMA units [38], as depicted in Figure 5. The appearance of signals at $2.3-2.5 \mathrm{ppm}$ and $3.38 \mathrm{ppm}$ was attributed to $-\mathrm{CH}_{2}$ and $\mathrm{CH}_{3} \mathrm{O}-$ protons arising from PEGMA units [3941]. The methyl protons for $-\mathrm{OCH}_{3}$ in MMA units were at $3.55 \mathrm{ppm}$, while $-\mathrm{CH}_{2} \mathrm{O}$ protons in PEGMA units appeared at $3.65 \mathrm{ppm}[24,32,34]$. Methylene protons of $-\mathrm{CH}_{2} \mathrm{OH}$ in HEMA and $-\mathrm{CH}_{2}$ in PEGMA gave a sharp signal around $4.2 \mathrm{ppm}[38-41]$.

Figure 6 shows the DSC curves of P(HEMA-co-MMA) copolymers (1b and $\mathbf{1 d})$, recorded between $0-180^{\circ} \mathrm{C}$. A substantial decrease in the glass transition temperature with increasing HEMA content was observed, which agreed with the literature [38]. The $T_{g}$ of $\mathrm{P}(\operatorname{HEMA}(20)-c o-\operatorname{MMA}(80))$ (1b) and P(HEMA(50)-co-MMA(50)) (1d) were detected 


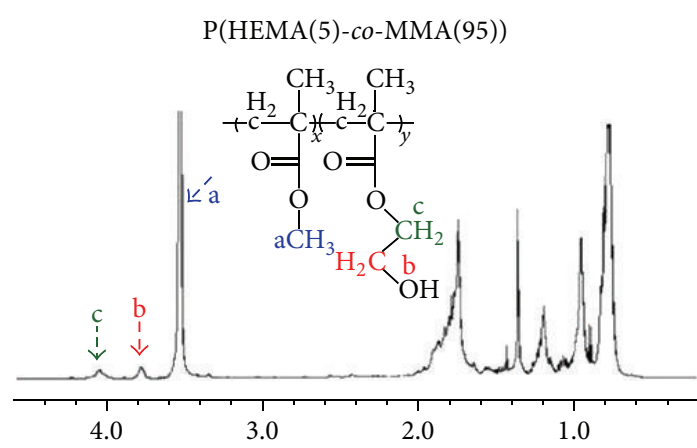

(a)

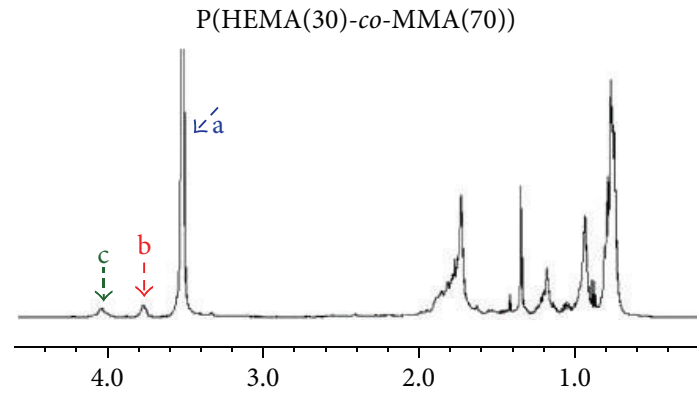

(c)

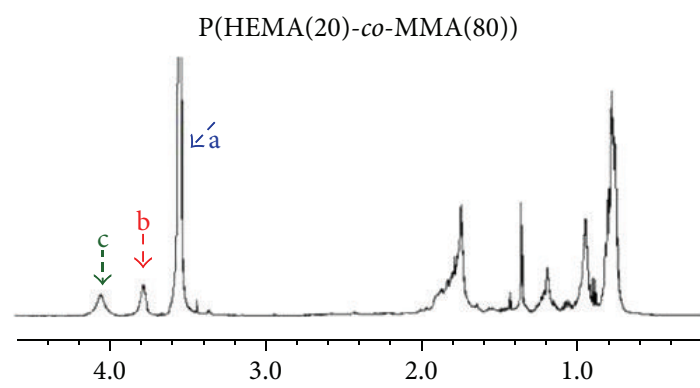

(b)

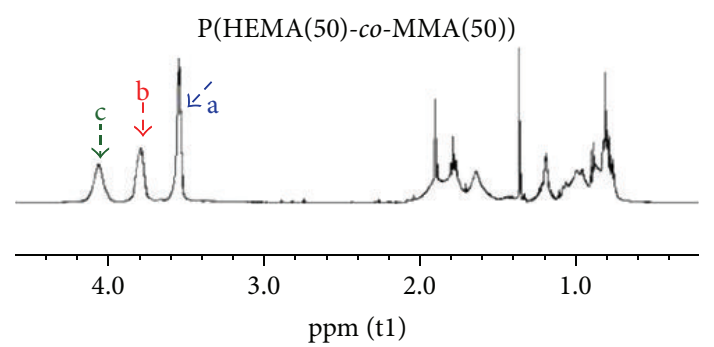

(d)

Figure $4:{ }^{1}$ H-NMR spectra of P(HEMA-co-MMA) copolymers (1a-1d).

TABLE 2: Compositions of P(HEMA-co-MMA) obtained from ${ }^{1} \mathrm{H}-\mathrm{NMR}$ data.

\begin{tabular}{lcc}
\hline $\begin{array}{l}\text { Comonomers in feed (volume } \\
\text { ratio) }\end{array}$ & $\begin{array}{c}\text { Comonomers in feed \% HEMA/\% MMA } \\
(\text { mol \%) }\end{array}$ & $\begin{array}{c}\text { Comonomers in polymer \% HEMA/\% } \\
\text { MMA (mol \%) }\end{array}$ \\
\hline HEMA(5)-MMA(95) & $4.4 / 95.6$ & $4.7 / 95.3$ \\
HEMA(20)-MMA(80) & $18.1 / 81.9$ & $18.5 / 81.5$ \\
HEMA(30)-MMA(70) & $27.4 / 72.6$ & $25.0 / 75.0$ \\
HEMA(50)-MMA(50) & $46.9 / 53.1$ & $49.1 / 50.9$ \\
\hline
\end{tabular}

aby volume, ${ }^{\mathrm{b}}$ by moles, and ${ }^{\mathrm{c}}$ calculated from ${ }^{\mathrm{l}} \mathrm{H}-\mathrm{NMR}$.

TABLE 3: Conditions ${ }^{\mathrm{a}}$ and results for the synthesis of P(HEMA-co-MMA)-block-PPEGMA.

\begin{tabular}{lccccc}
\hline Entry & Macroinitiator & P(HEMA-co-MMA)-block-PPEGMA & ${ }^{\mathrm{b}} M_{n, \mathrm{GPC}}$ & ${ }^{\mathrm{c}} M_{n, \text { theo }}$ & ${ }^{\mathrm{d}} M_{w} / M_{n}$ \\
\hline $\mathbf{1}$ & $\mathbf{( 1 b )}$ & $\mathbf{( 2 b )}$ & 112620 & 108080 \\
$\mathbf{2}$ & $\mathbf{( 1 d )}$ & $\mathbf{( 2 d )}$ & 58040 & 60440 \\
\hline
\end{tabular}

${ }^{\mathrm{a}}[\mathrm{MeOH}] /$ water $=2: 1 \mathrm{v} / \mathrm{v},[\mathrm{M}] /[\mathrm{I}] /[\mathrm{CuBr}] /[$ PMDETA $]: 400 / 1 / 1 / 2$; temperature: r.t. ${ }^{\mathrm{b}}$ determined from GPC measurements. ${ }^{\mathrm{c}}$ calculated by using formula: $M_{n \text {,theo }}=M_{w \text {,monomer }} \times[$ Monomer $] /[$ Initiator $] \times$ Conv. $+M_{w \text {,initiator }}{ }^{\mathrm{d}} M_{n}$ : the number average molecular weight; $M_{w}$ : the weight average molecular weight.

around $100^{\circ} \mathrm{C}$ and $57^{\circ} \mathrm{C}$ [38], respectively. PHEMA and PMMA homopolymers as well as their copolymers are amorphous and do not show any melting temperature, as expected. Figure 7 shows DSC analysis of P(HEMA-coMMA)-block-PPEGMA (2b and $\mathbf{2 d}$ ), evaluated during the heating process from -48 to $180^{\circ} \mathrm{C}$. P(HEMA-co-MMA)block-PPEGMA shows a $T_{m}$ due to the presence of crystalline domains originating from PPEGMA blocks. The presence of $T_{m}$ at around $0^{\circ} \mathrm{C}$ supports the block copolymer formation. It is also noteworthy that $T_{m}$ values for (2b) and (2d) are almost the same although different feed ratios of precursor
$\mathrm{P}$ (HEMA-co-MMA) were employed in the block copolymer formation, which might have resulted in an evident shifting of $T_{m}$ since variation of HEMA and MMA content can possibly affect the crystallinity in the microstructure. However, a careful inspection reveals that the final copolymer content (in mol) of $\mathbf{2 b}$ (HEMA/MMA/PEGMA 1/4/22) and $\mathbf{2 d}$ (HEMA/MMA/PEGMA 4/4/22) is very close and the fact that $T_{m}$ values are nearly the same is just as expected.

The thermal stabilities of P(HEMA-co-MMA) copolymers (1b and $\mathbf{1 d}$ ) and P(HEMA-co-MMA)-block-PPEGMA (2b and 2d) block copolymers were analyzed as well, as 
TABLE 4: Temperatures of various decompositions and char yield in $\mathrm{N}_{2}$ at $750^{\circ} \mathrm{C}$.

\begin{tabular}{lcccc}
\hline Sample & $\begin{array}{c}\text { Temperature of 5\% } \\
\text { weight loss }\left({ }^{\circ} \mathrm{C}\right)\end{array}$ & $\begin{array}{c}\text { Temperature of } \\
10 \% \text { weight loss } \\
\left({ }^{\circ} \mathrm{C}\right)\end{array}$ & $\begin{array}{c}\text { Temperature of the } \\
\text { rapid weight loss } \\
T_{\max }\left({ }^{\circ} \mathrm{C}\right)\end{array}$ & $\begin{array}{c}\text { Char yield at } 750 \\
\left({ }^{\circ} \mathrm{C}\right) \text { in } N_{2}(\mathrm{wt} \%)\end{array}$ \\
\hline P(HEMA(20)-co-MMA(80)) & 213 & 292 & 367 & 0 \\
P(HEMA(50)-co-MMA(50)) & 184 & 251 & 371 & 0 \\
P(HEMA(20)-co-MMA(80))-block-PPEGMA & 185 & 277 & 327 & 0 \\
P(HEMA(50)-co-MMA(50))-block-PPEGMA & 298 & 334 & 350 & 0 \\
\hline
\end{tabular}

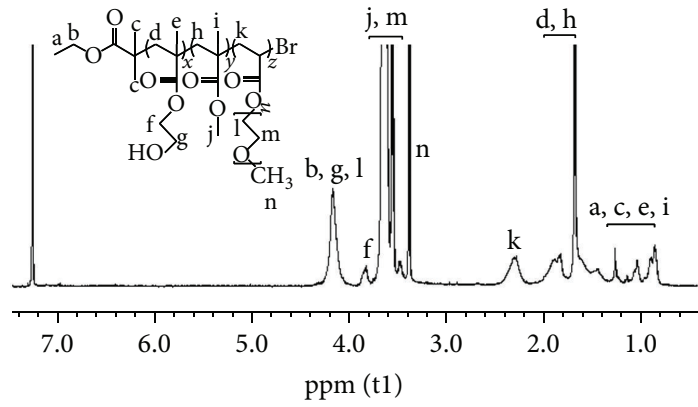

Figure 5: The ${ }^{1} \mathrm{H}$-NMR spectrum of P(HEMA-co-MMA)-blockPPEGMA (2b, 2d).

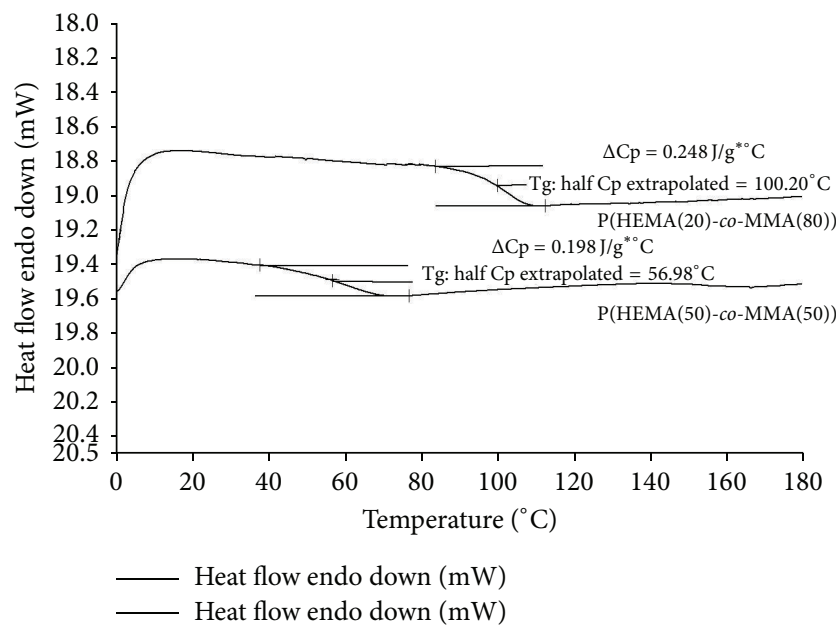

Figure 6: The DSC curves of P(HEMA(20)-co-MMA(80)) (1b) and $\mathrm{P}(\operatorname{HEMA}(50)$-co-MMA(50)) (1d) copolymers.

shown in Figure 8. The TGA curves of P(HEMA-co-MMA) copolymers with varying composition of HEMA indicated a thermal stability up to $340-350^{\circ} \mathrm{C}$ [38]. On the other hand, in the analysis of $\mathrm{P}$ (HEMA-co-MMA)-block-PPEGMA block copolymers, the decomposition temperatures are shifted to relatively lower values with the incorporation of PEGMA units.

The temperature of $5 \%$ weight loss, the temperature of $10 \%$ weight loss, the temperature of the rapid weight loss $\left(T_{\max }\right)$ before $750^{\circ} \mathrm{C}$, and the char yield at $750^{\circ} \mathrm{C}$ in nitrogen are summarized in Table 4.

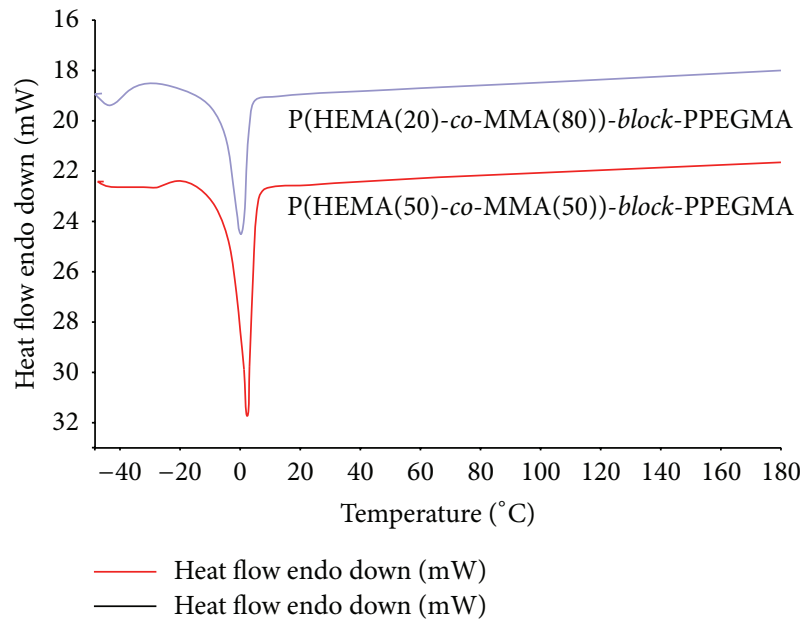

Figure 7: The DSC of P(HEMA-co-MMA)-block-PPEGMA (2b, 2d).

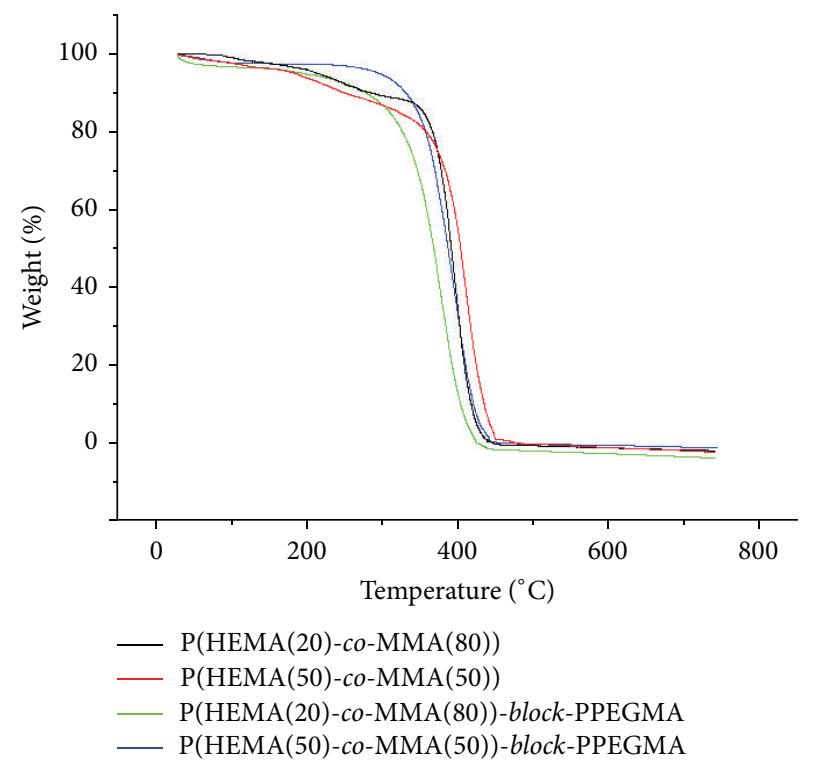

FIgURE 8: TGA curves of P(HEMA-co-MMA) (1b, 1d) and P(HEMA-co-MMA)-block-PPEGMA (2b, 2d).

Propargyl side-functional block copolymers, alkyneP(HEMA-co-MMA)-block-PPEGMA (3b and 3d), were prepared by the Steglich esterification between hydroxyl groups of HEMA and propiolic acid in the presence of DCC and 


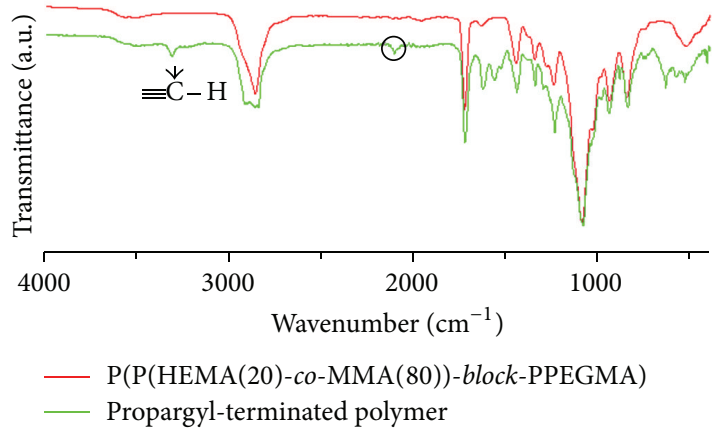

(a)

FIgURE 9: The FT-IR spectra of P(HEMA-co-MMA)-block-PPEGMA

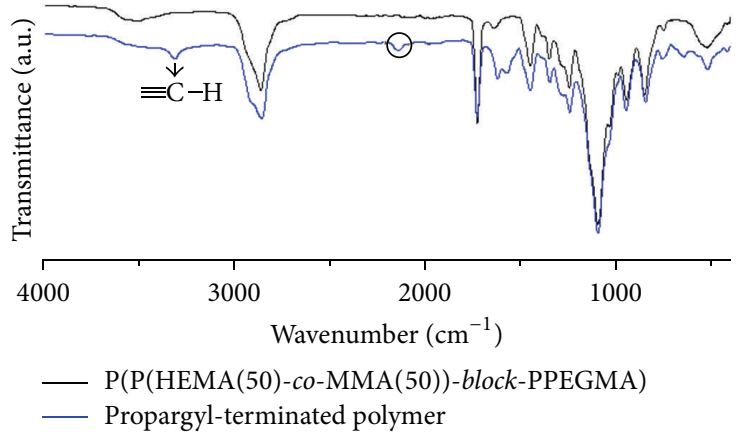

(b)
DMAP at room temperature [35]. The GPC analysis provided evidence for the success of reaction. As expected, there was a slight increase in the $M_{n}$ values.

For P(HEMA(20)-MMA(80))-b-PPEGMA (2b), $M_{n}$ changed from 112620 to 113350 (PDI = 1.53), while, for P(HEMA(50)-MMA(50))-b-PPEGMA) (2d), there was a change from 58040 to 59514 (PDI = 1.39), which showed the incorporation of propargyl units.

Further proof was supplied by FT IR analysis as depicted in Figure 9. As compared to the spectrum of P(HEMA-coMMA)-block-PPEGMA, two new bands (2b, 2d) appeared at around 2350 and $3320 \mathrm{~cm}^{-1}$ in the spectrum of alkyneP(HEMA-co-MMA)-block-PPEGMA (3b, 3d), which were assigned to the stretching vibration of the alkyne group [35].

Finally, to assess the applicability of alkyne-P(HEMAco-MMA)-block-PPEGMA in postfunctionalization, $\mathbf{3 b}$ and 3d having different molecular weights were click coupled with 2,3,4,5,6-pentafluorobenzyl azide. For this purpose, first, 2,3,4,5,6-pentafluorobenzyl azide was prepared upon reaction between their halo-compounds and $\mathrm{NaN}_{3}$ in DMF at room temperature. The halogen atoms were substituted with azide groups via nucleophilic substitution. The FT-IR spectra are illustrated in Figure 10. The appearance of sharp $-\mathrm{N}_{3}$ stretching bands between $2110 \mathrm{~cm}^{-1}$ and $2090 \mathrm{~cm}^{-1}$ for 2,3,4,5,6-pentafluorobenzyl azide supported that azidation was successful [32-36, 42, 43].

In the second step, $\mathrm{Cu}(\mathrm{I})$ catalyzed Huisgen 1,3-dipolar cycloaddition (CuAAC) was carried out between propargyl side functionalities on the backbone and 2,3,4,5,6pentafluorobenzyl azide. The ${ }^{1} \mathrm{H}-\mathrm{NMR}$ spectra of the click products are illustrated in Figure 11. The appearance of the new signals at 7.64 (f) and 5.59 (e) ppm, regarding the methine proton and the methylene protons adjacent to the triazole ring, respectively, were observed [32, 34-36, 42, 43].

Further evidence for the incorporation of 2,3,4,5,6pentafluorobenzene was provided by ${ }^{19} \mathrm{~F}-\mathrm{NMR}$ analysis as presented in Figure 12. The signals which appeared in the spectrum of 2,3,4,5,6-pentafluorobenzyl azide also existed in that of click product. The signals detected at $-142 \mathrm{ppm}$, $-151 \mathrm{ppm}$, and $-161 \mathrm{ppm}$ originated from the aromatic fluorines: $2 \mathrm{~F}$ at $o$-position, $1 \mathrm{~F}$ at $p$-position, and $2 \mathrm{~F}$ at $m$-position, respectively [44].

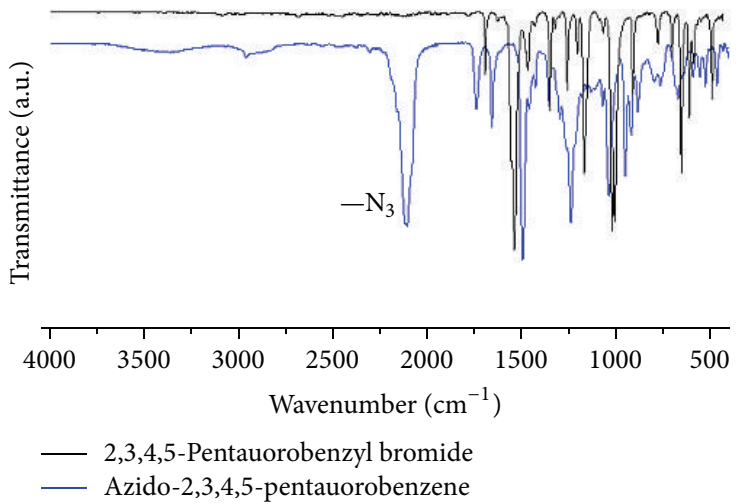

FIGURE 10: The FT-IR spectra of 2,3,4,5,6-pentafluorobenzyl chloride and azido-2,3,4,5-pentafluorobenzene.

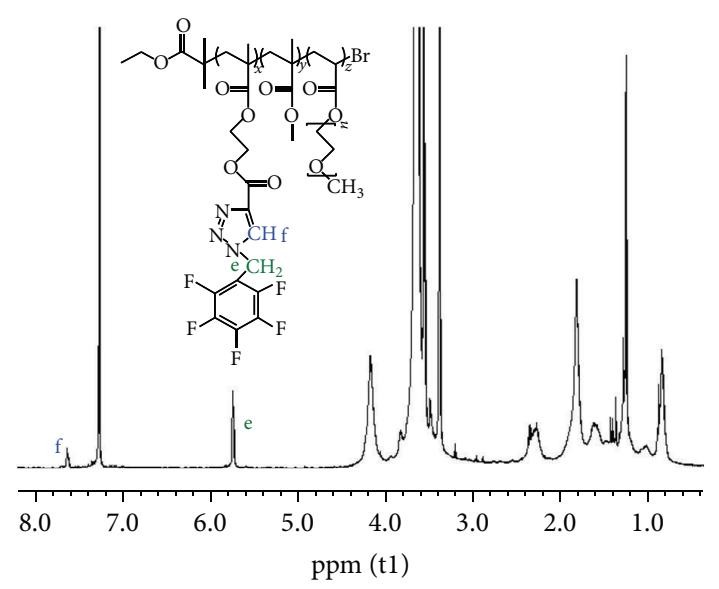

FIGURE 11: The ${ }^{1} \mathrm{H}-\mathrm{NMR}$ spectra of the click product (4).

\section{Conclusions}

The strategy of combining ATRP with $\mathrm{Cu}(\mathrm{I})$ catalyzed Huisgen 1,3-dipolar cycloaddition (CuAAC) in the preparation of a novel clickable amphiphilic block copolymer was demonstrated. First, P(HEMA-co-MMA) copolymers were prepared via ATRP. Molar ratio of MMA and HEMA was varied 


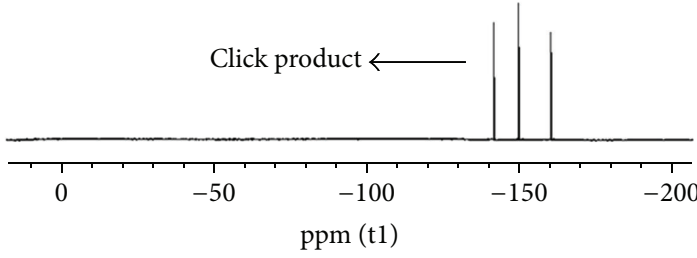

(a)

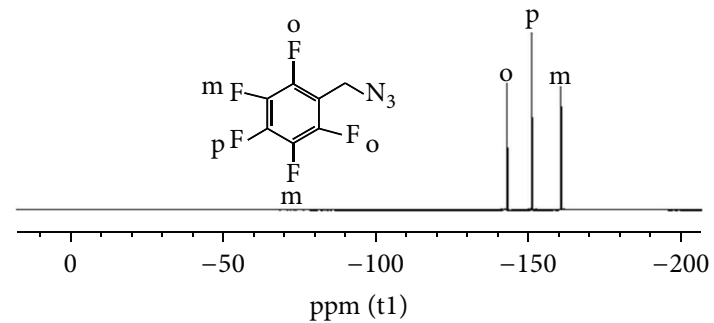

(b)

Figure 12: (a) The ${ }^{19}$ F-NMR spectra of click product; (b) the ${ }^{19}$ F-NMR spectra of 2,3,4,5,6-pentafluorobenzyl azide.

to get random copolymers with different HEMA contents. The copolymer compositions were obtained from ${ }^{1} \mathrm{H}-\mathrm{NMR}$ and agreed well with the charged monomer ratio in feed. Polymerization of poly(ethylene glycol) methyl ether acrylate was carried out via ATRP using P(HEMA(20)-co-MMA(80)) (1b) and P(HEMA(50)-co-MMA(50)) (1d) as macroinitiator to get block copolymers. GPC analysis of the obtained block copolymers was measured as $M_{n}=112620(\mathrm{PDI}=1.58)$ and $M_{n}=58040(\mathrm{PDI}=1.39)$, respectively. Both ${ }^{1} \mathrm{H}-\mathrm{NMR}$ and FT-IR spectra showed peaks associated with MMA, HEMA, and PEGMA repeating units. Thermal properties of the copolymers and the block copolymers were also studied by TGA and DSC. For the copolymers, a thermal stability of up to $340-350^{\circ} \mathrm{C}$ was detected. In the next step, alkyneP(HEMA-co-MMA)-block-PPEGMA (3b, 3d) was prepared by the Steglich esterification between hydroxyl groups of HEMA and propiolic acid in the presence of DCC and DMAP at room temperature. Finally, $\mathrm{Cu}(\mathrm{I})$ catalyzed Huisgen 1,3-dipolar cycloaddition (CuAAC) was employed as a tool for postfunctionalization. The click coupling between propargyl side functionalities on the backbone and 2,3,4,5,6pentafluorobenzyl azide were evidenced by ${ }^{1} \mathrm{H}-\mathrm{NMR}$ and ${ }^{19} \mathrm{~F}$-NMR. This synthetic route might be useful in tuning the lengths of the hydrophilic and hydrophobic segments in amphiphilic polymers as well as the average number of functionalities situated in the side chain.

\section{Conflict of Interests}

The authors declare that there is no conflict of interests regarding the publication of this paper.

\section{Acknowledgment}

This work was supported by the Scientific Research Fund of Fatih University under the Project no. P50021002_2.

\section{References}

[1] B. Jiang, L. Zhang, J. Shi et al., "Synthesis, characterization and bulk properties of well-defined poly(hexafluorobutyl methacrylate)-block-poly(glycidyl methacrylate) via consecutive ATRP," Journal of Fluorine Chemistry, vol. 153, pp. 74-81, 2013.
[2] M. P. Krafft, "Controlling phospholipid self-assembly and film properties using highly fluorinated components-fluorinated monolayers, vesicles, emulsions and microbubbles," Biochimie, vol. 94, no. 1, pp. 11-25, 2012.

[3] E. Amado and J. Kressler, "Triphilic block copolymers with perfluorocarbon moieties in aqueous systems and their biochemical perspectives," Soft Matter, vol. 7, no. 16, pp. 7144-7149, 2011.

[4] H. Nakahara, M. Tsuji, Y. Sato, M. P. Krafft, and O. Shibata, "Langmuir monolayer miscibility of single-chain partially fluorinated amphiphiles with tetradecanoic acid," Journal of Colloid and Interface Science, vol. 337, no. 1, pp. 201-210, 2009.

[5] M. Broniatowski and P. Dynarowicz-Łatka, "Semifluorinated alkanes-primitive surfactants of fascinating properties," Advances in Colloid and Interface Science, vol. 138, no. 2, pp. 63-83, 2008.

[6] M. P. Krafft, "Fluorocarbons and fluorinated amphiphiles in drug delivery and biomedical research," Advanced Drug Delivery Reviews, vol. 47, no. 2-3, pp. 209-228, 2001.

[7] K. K. Goli, O. J. Rojas, and J. Genzer, "Formation and antifouling properties of amphiphilic coatings on polypropylene fibers," Biomacromolecules, vol. 13, no. 11, pp. 3769-3779, 2012.

[8] H. Peng, K. J. Thurecht, I. Blakey, E. Taran, and A. K. Whittaker, "Effect of solvent quality on the solution properties of assemblies of partially fluorinated amphiphilic diblock copolymers," Macromolecules, vol. 45, no. 21, pp. 8681-8690, 2012.

[9] P. Scholtysek, Z. Li, J. Kressler, and A. Blume, "Interactions of DPPC with semitelechelic poly(glycerol methacrylate)s with perfluoroalkyl end groups," Langmuir, vol. 28, no. 44, pp. 1565115662, 2012.

[10] Z. Zhao, H. Ni, Z. Han et al., "Effect of surface compositional heterogeneities and microphase segregation of fluorinated amphiphilic copolymers on antifouling performance," ACS Applied Materials and Interfaces, vol. 5, no. 16, pp. 78087818, 2013.

[11] A. Bruno, "Controlled radical (Co)polymerization of fluoromonomers," Macromolecules, vol. 43, no. 24, pp. 10163-10184, 2010.

[12] N. M. L. Hansen, K. Jankova, and S. Hvilsted, "Fluoropolymer materials and architectures prepared by controlled radical polymerizations," European Polymer Journal, vol. 43, no. 2, pp. 255-293, 2007.

[13] A. Chakrabarty and N. K. Singha, "Tailor-made polyfluoroacrylate and its block copolymer by RAFT polymerization in miniemulsion; improved hydrophobicity in the core-shell block copolymer," Journal of Colloid and Interface Science, vol. 408, pp. 66-74, 2013. 
[14] J. M. Bak and H. Lee, "Novel thermoresponsive fluorinated double-hydrophilic poly[N-(2,2- difluoroethyl)acrylamide]-b[N-(2-fluoroethyl)acrylamide] block copolymers," Journal of Polymer Science A: Polymer Chemistry, vol. 51, no. 9, pp. 19761982, 2013.

[15] T. L. Bucholz and Y. Loo, "Phase behavior of near-monodisperse semifluorinated diblock copolymers by atom transfer radical polymerization," Macromolecules, vol. 39, no. 18, pp. 6075-6080, 2006.

[16] G.-D. Fu, Z.-L. Yuan, E.-T. Kang, K.-G. Neoh, D. M. Lai, and A. C. H. Huan, "Nanoporous ultra-low-dielectricconstant fluoropolymer films via selective UV decomposition of poly(pentafluorostyrene)-block-poly(methyl methacrylate) copolymers prepared using atom transfer radical polymerization," Advanced Functional Materials, vol. 15, no. 2, pp. 315-322, 2005.

[17] W. Guo, X. Tang, J. Xu et al., "Synthesis, characterization, and property of amphiphilic fluorinated abc-type triblock copolymers," Journal of Polymer Science A: Polymer Chemistry, vol. 49, no. 7, pp. 1528-1534, 2011.

[18] E. Martinelli, S. Agostini, G. Galli et al., "Nanostructured films of amphiphilic fluorinated block copolymers for fouling release application," Langmuir, vol. 24, no. 22, pp. 13138-13147, 2008.

[19] G. P. He, G. W. Zhang, J. P. Hu et al., "Low-fluorinated homopolymer from heterogeneous ATRP of 2,2,2-trifluoroethyl methacrylate mediated by copper complex with nitrogen-based ligand," Journal of Fluorine Chemistry, vol. 132, no. 9, pp. 562$572,2011$.

[20] N. M. L. Hansen, M. Gerstenberg, D. M. Haddleton, and S. Hvilsted, "Synthesis, characterization, and bulk properties of amphiphilic copolymers containing fluorinated methacrylates from sequential copper-mediated radical polymerization," Journal of Polymer Science A: Polymer Chemistry, vol. 46, no. 24, pp. 8097-8111, 2008.

[21] N. M. L. Hansen, D. M. Haddleton, and S. Hvilsted, "Fluorinated bio-acceptable polymers via an ATRP macroinitiator approach," Journal of Polymer Science A: Polymer Chemistry, vol. 45, no. 24, pp. 5770-5780, 2007.

[22] Y. Chen, L. Chen, H. Nie, E. T. Kang, and R. H. Vora, "Fluorinated polyimides grafted with poly(ethylene glycol) side chains by the RAFT-mediated process and their membranes," Materials Chemistry and Physics, vol. 94, no. 2-3, pp. 195-201, 2005.

[23] D. Burger, J. Gisin, and E. Bartsch, "Synthesis of sterically stabilized perfluorinated aqueous latices," Colloids and Surfaces A: Physicochemical and Engineering Aspects, vol. 442, pp. 123131, 2014.

[24] Y. Liu, J. Y. Lee, E. T. Kang, P. Wang, and K. L. Tan, "Synthesis, characterization and electrochemical transport properties of the poly(ethyleneglycol)-grafted poly(vinylidenefluoride) nanoporous membranes," Reactive and Functional Polymers, vol. 47, no. 3, pp. 201-213, 2001.

[25] P. Wang, K. L. Tan, and E. T. Kang, "Surface modification of poly(tetrafluoroethylene) films via grafting of poly(ethylene glycol) for reduction in protein adsorption," Journal of Biomaterials Science, Polymer Edition, vol. 11, no. 2, pp. 169-186, 2000.

[26] Y. Nakayama, M. Miyamura, Y. Hirano, K. Goto, and T. Matsuda, "Preparation of poly(ethylene glycol)-polystyrene block copolymers using photochemistry of dithiocarbamate as a reduced cell-adhesive coating material," Biomaterials, vol. 20, no. 10, pp. 963-970, 1999.
[27] G. D. Fu, Z. H. Shang, L. Hong, E. T. Kang, and K. G. Neoh, "Nanoporous, ultralow-dielectric-constant fluoropolymer films from agglomerated and crosslinked hollow nanospheres of poly (pentafluorostyrene)-block-poly(divinylbenzene)," Advanced Materials, vol. 17, no. 21, pp. 2622-2626, 2005.

[28] M. Paz-Pazos and C. Pugh, "Synthesis of optically active copolymers of 2,3,4,5, 6-pentafluorostyrene and $\beta$-pinene with low surface energies," Journal of Polymer Science A: Polymer Chemistry, vol. 44, no. 9, pp. 3114-3124, 2006.

[29] A. M. Granville, S. G. Boyes, B. Akgun, M. D. Foster, and W. J. Brittain, "Thermoresponsive behavior of semifluorinated polymer brushes," Macromolecules, vol. 38, no. 8, pp. 3263-3270, 2005.

[30] H. C. Kolb, M. G. Finn, and K. B. Sharpless, "Click chemistry: diverse chemical function from a few good reactions," Angewandte Chemie - International Edition, vol. 40, no. 11, pp. 20042021, 2001.

[31] V. V. Rostovtsev, G. Green, V. V. Fokin, and K. B. Sharpless, "A stepwise huisgen cycloaddition process: copper(I)-catalyzed regioselective ligation of azides and terminal alkynes," Angewandte Chemie International Edition, vol. 41, no. 14, pp. 25962599, 2002.

[32] M. Ergin, B. Kiskan, B. Gacal, and Y. Yagci, "Thermally curable polystyrene via click chemistry," Macromolecules, vol. 40, no. 13, pp. 4724-4727, 2007.

[33] G. D. Fu, E. T. Kang, and K. G. Neoh, “Three-dimensionally ordered porous membranes prepared via self-assembly and reverse micelle formation from well-defined amphiphilic block copolymers," Langmuir, vol. 21, no. 8, pp. 3619-3624, 2005.

[34] M. Degirmenci and N. Genli, "Synthesis of well-defined telechelic macrophotoinitiator of polystyrene by combination of ATRP and click chemistry," Macromolecular Chemistry and Physics, vol. 210, no. 19, pp. 1617-1623, 2009.

[35] D. Sinirlioglu and A. E. Muftuoglu, "Synthesis of an inorganicorganic hybrid material based on polyhedral oligomeric silsesquioxane and polystyrene via nitroxide-mediated polymerization and click reactions," Designed Monomers and Polymers, vol. 14, no. 3, pp. 273-286, 2011.

[36] O. Eren, M. Gorur, B. Keskin, and F. Yilmaz, "Synthesis and characterization of ferrocene end-capped poly $(\varepsilon-$ caprolactone)s by a combination of ring-opening polymerization and "click" chemistry techniques," Reactive and Functional Polymers, vol. 73, no. 1, pp. 244-253, 2013.

[37] S. Arifuzzaman, A. E. Özçam, K. Efimenko, D. A. Fischer, and J. Genzer, "Formation of surface-grafted polymeric amphiphilic coatings comprising ethylene glycol and fluorinated groups and their response to protein adsorption," Biointerphases, vol. 4, no. 2, pp. FA33-FA44, 2009.

[38] E. Vargün, M. Sankir, B. Aran, N. D. Sankir, and A. Usanmaz, "Synthesis and characterization of 2-hydroxyethyl methacrylate (HEMA) and methyl methacrylate (MMA) l," Journal of Macromolecular Science A: Pure and Applied Chemistry, vol. 47, no. 3, pp. 235-240, 2010.

[39] M. M. Ali and H. D. H. Stöver, "Well-defined amphiphilic thermosensitive copolymers based on poly(ethylene glycol monomethacrylate) and methyl methacrylate prepared by atom transfer radical polymerization," Macromolecules, vol. 37, no. 14, pp. 5219-5227, 2004.

[40] B. H. Tan, H. Hussain, Y. Liu, C. B. He, and T. P. Davis, "Synthesis and self-assembly of brush-type poly[poly(ethylene 
glycol)methyl ether methacrylate]-block-poly(pentafluorostyrene) amphiphilic diblock copolymers in aqueous solution," Langmuir, vol. 26, no. 4, pp. 2361-2368, 2010.

[41] B. Kim, H. Lee, S. Jeong, J. Lee, and H. Paik, "Amphiphilic gradient copolymer of [poly(ethylene glycol) methyl ether] methacrylate and styrene via atom transfer radical polymerization," Macromolecular Research, vol. 19, no. 12, pp. 1257-1263, 2011.

[42] M. Degirmenci and N. Genli, "Synthesis of poly(cyclohexene oxide)-block-polystyrene by combination of radical-promoted cationic polymerization, atom transfer radical polymerization and click chemistry," Polymer International, vol. 59, no. 6, pp. 859-866, 2010.

[43] O. Karagollu, M. Gorur, F. Gode, B. Sennik, and F. Yilmaz, "Phosphate ion sensors based on triazole connected ferrocene moieties," Sensors and Actuators B, vol. 193, pp. 788-798, 2014.

[44] K. T. Powell, C. Cheng, K. L. Wooley, A. Singh, and M. W. Urban, "Complex amphiphilic networks derived from diamineterminated poly(ethylene glycol) and benzylic chloride-functionalized hyperbranched fluoropolymers," Journal of Polymer Science A: Polymer Chemistry, vol. 44, no. 16, pp. 4782-4794, 2006. 

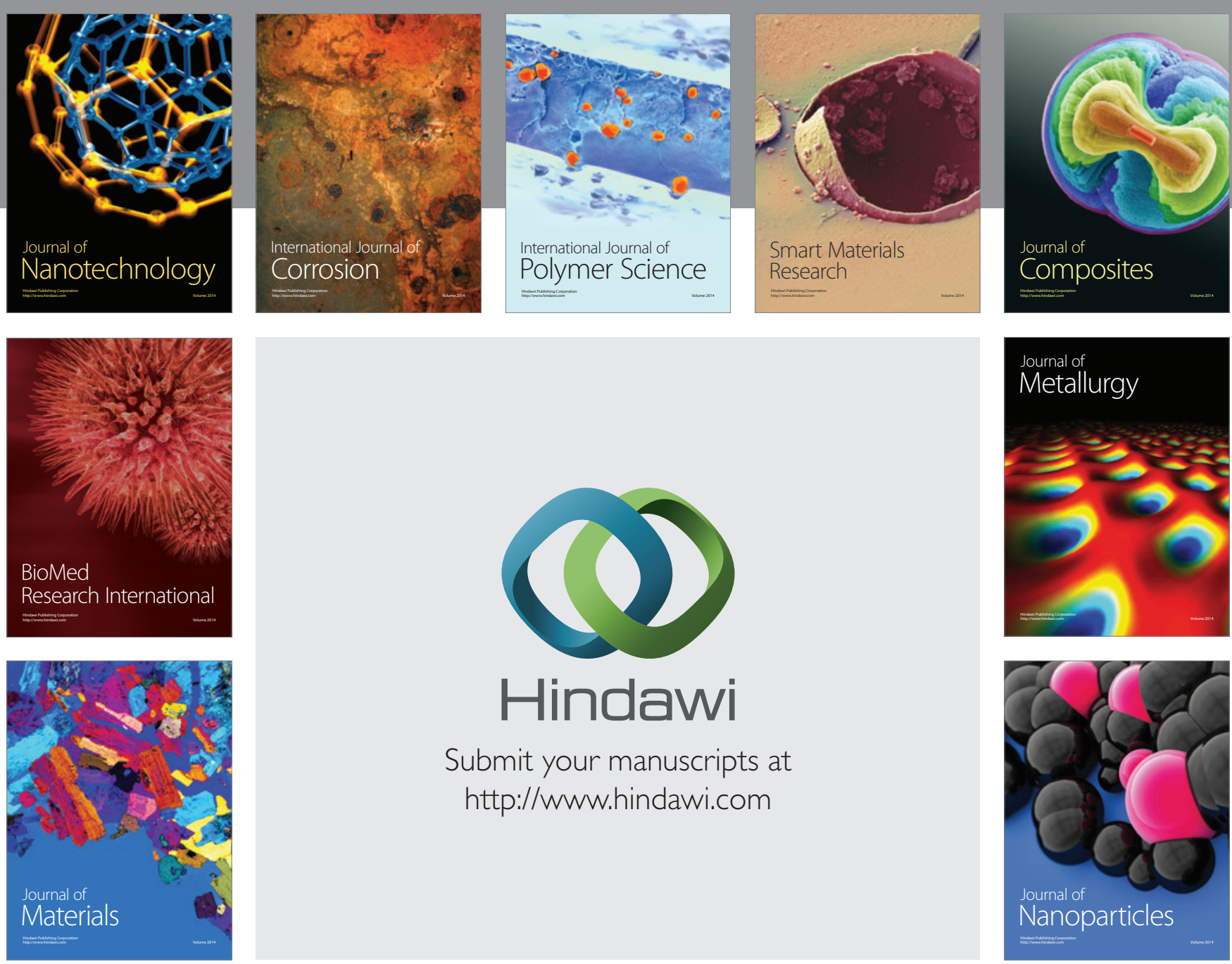

Submit your manuscripts at http://www.hindawi.com
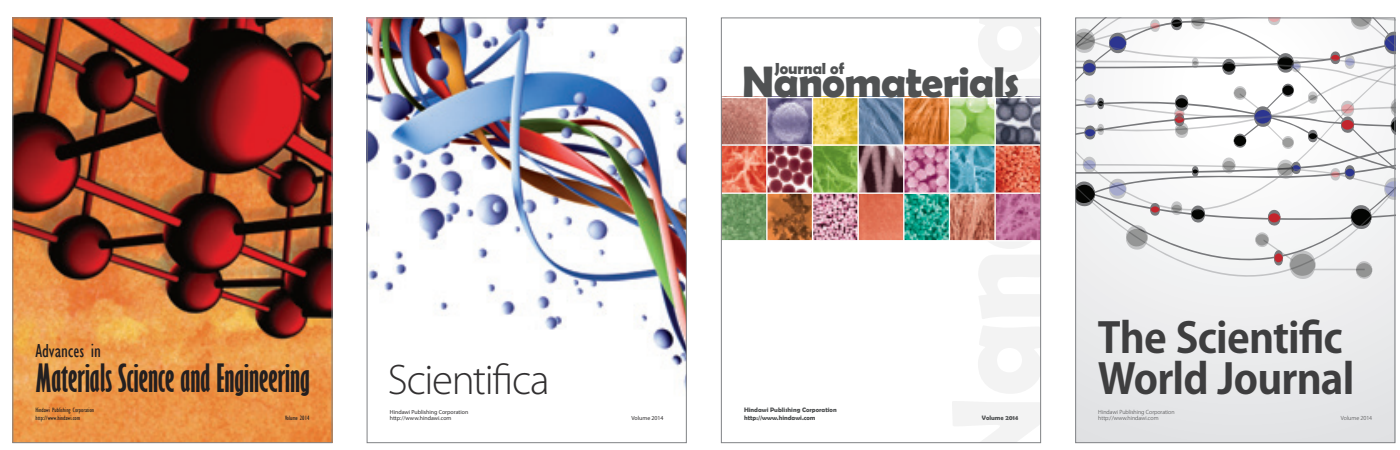

\section{The Scientific World Journal}
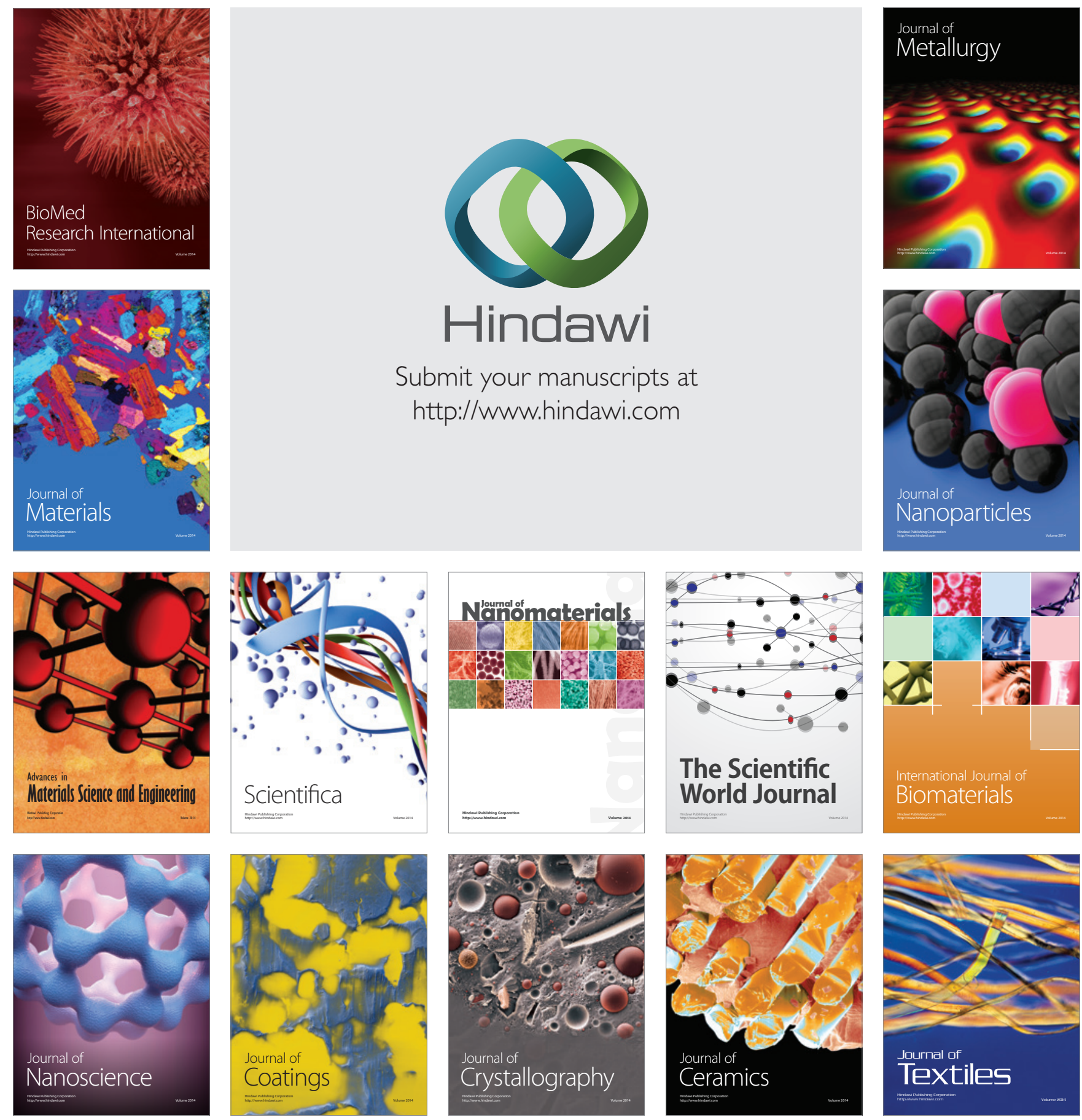